\title{
Hemoprotozoa of domestic animals in France: Prevalence and molecular characterization
}

\author{
A. Criado-Fornelio ${ }^{\mathrm{a}, *}$, A. Buling ${ }^{\mathrm{a}}$, J.L. Pingret ${ }^{\mathrm{b}}$, M. Etievant ${ }^{\mathrm{b}}$, C. Boucraut-Baralon ${ }^{\mathrm{b}}$, \\ A. Alongi ${ }^{c}$, A. Agnone ${ }^{c}$, A. Torina ${ }^{c}$ \\ a Parasitology Laboratory, Department of Microbiology and Parasitology, Faculty of Pharmacy, University of Alcalá, 28871 Alcalá de Henares, Spain \\ ${ }^{\mathrm{b}}$ Scanelis, Veterinary Diagnostic Laboratory, ENVT, 23, chemin des Capelles, 31076 Toulouse Cedex 3, France \\ ${ }^{\mathrm{c}}$ National Reference Centre for Anaplasma, Babesia, Rickettsia and Theileria (CRABART), Zooprophylactic Institute of Sicily (IZS), Via Gino Marinuzzi 3, \\ 90129 Palermo, Italy
}

\section{A R T I C L E I N F O}

\section{Article history:}

Received 6 June 2008

Received in revised form 3 October 2008

Accepted 3 October 2008

\section{Keywords:}

Epizootiology

Hepatozoon canis

Piroplasmida

PCR

\begin{abstract}
A B S T R A C T
Very limited information is available on epizootiology of haematozoan infections in French domestic animals. In an attempt to address this issue, prevalence of piroplasmida was studied in carnivores and ruminants, whereas prevalence of Hepatozoon spp. was only investigated in carnivores. In total, 383 animals were included in the survey (namely 116 cats, 108 dogs, 91 sheep and 68 cows). Parasite diagnosis was carried out using molecular methods such as PCR and sequencing of the $18 \mathrm{~S}$ rRNA gene. In addition, ruminant samples were analyzed with the reverse line blotting technique (RLB). Results of RLB and PCR plus sequencing were in total agreement.

In carnivores, haematozoan prevalence was close to $1 \%$. Two cats were infected by $H$. canis (1.7\% prevalence) and one of them was co-infected by Cytauxzoon sp. (0.8\%). This represents the first finding of both pathogens in French cats. One dog was infected by $H$. canis $(0.9 \%)$ and another by Babesia canis vogeli $(0.9 \%)$.

In ruminants, haematozoan prevalence (piroplasmida) was significantly higher than in carnivores (4.8\% in sheep and $8.8 \%$ in cow). Theileria ovis was found in 1 sheep, Theileria sp. in 2 sheep, Theileria buffeli in 5 cows and B. major in 1 cow.

Evidence presented in this contribution indicates that haematic protozoa are not widely distributed in domestic mammal populations of France.
\end{abstract}

(c) 2008 Elsevier B.V. All rights reserved.

\section{Introduction}

Members of the order Piroplasmida (like the genera Babesia, Theileria and Cytauxzoon) and Adeleorina (like Hepatozoon canis) are apicomplexan protozoa. They live in blood cells of vertebrates and are transmitted by ticks. Both piroplasmida and Hepatozoon are causative agents of important zoonotic diseases. Traditionally these organisms have been diagnosed by low sensitivity techniques, such as microscopic examination of blood smears. Following the

\footnotetext{
* Corresponding author. Tel.: +34 918854728; fax: +34 918854663 E-mail address: angel.criado@uah.es (A. Criado-Fornelio).
}

advent of new molecular diagnostic techniques Babesia, Theileria and Hepatozoon have been diagnosed with increased frequency in domestic animals. The same is true for human babesiosis (Gratz, 2004). In addition, DNA sequencing combined with phylogenetic analysis has revealed the existence of some new haematozoans in recent years (Allsopp and Allsopp, 2006). It is therefore generally accepted among parasitologists that emergent diseases caused by piroplasmida or Hepatozoon pose serious health risks both for animal and human (Harrus and Baneth, 2005).

Many studies on the biogeography of tick-borne haematozoans have been published during the last decade, but precise details of their epizootiology are still lacking for 
some European countries (Anon., 2007). This is particularly true of France, where only a few studies on the presence of theileriosis, babesiosis or hepatozoonosis have been carried out (L'Hostis and Seegers, 2002; Devos and Geysen, 2004; Bourdoiseau, 2006; Criado-Fornelio et al., 2007b). With the aim of filling this gap in the knowledge of protozoa biogeography, this communication reports on a study of hematozoans (namely piroplasmida and Hepatozoon sp.) in France. Techniques such as PCR, RLB and sequencing of the 18S rRNA gene were employed to diagnose and identify haematozoans in a representative number of domestic animals.

\section{Materials and methods}

During the survey period (December 2006-July 2007), blood samples from some 116 cats, 108 dogs, 91 sheep and 68 cows were sent by veterinarians to the Scanelis laboratory (Toulouse, France) for diagnosis. Blood specimens were collected into EDTA Vacutainer ${ }^{\circledR}$ tubes (Franklin Lakes, USA) by veterinarians. Blood samples were refrigerated and sent to the laboratory in a cold pack. Samples from ruminants were taken from animals showing no signs of disease, whereas samples from cats or dogs were obtained from symptomatic animals (showing signs related to infection with pathogens such as viruses, bacteria or parasites). Thirty-five percent of the cats were from the South of France, 19\% from the Centre, $42 \%$ from the North, $1 \%$ from overseas and 3\% were of unknown location. In dog the proportion of samples by geographic origin was as follows: $50 \%$ South, 30\% Centre, $17 \%$ North and 3\% overseas. Most of the ruminant samples came from Southern France (100\% of ovine and $79 \%$ of bovine).

All of the samples were studied in Spain by standard PCR (piroplasmida) or qPCR (Hepatozoon) and sequencing of the 18S rRNA gene. In addition, ruminant samples were analyzed at the Crabart laboratory in Italy by RLB, to obtain alternative diagnostic results by a more sensitive procedure. Small animal samples were not analyzed by RLB, due to the absence of suitable probes for identification of the diverse species of carnivore piroplasmida. DNA was extracted from $200 \mu \mathrm{l}$ of each blood specimen. The Nucleospin blood isolation kit (Macherey-Nagel, Düren, Germany) was employed in France for DNA extraction, following manufacturer's instructions. Purified DNA samples were stored at $-20^{\circ} \mathrm{C}$ and finally sent to Spain/Italy for molecular diagnosis in a cold package. Standard PCR was employed for diagnosis of piroplasmida (CriadoFornelio et al., 2003b). The piroplasmida PCR was performed with primers BT1-F (5'-GGTTGATCCTGCCAGTAGT- $\left.3^{\prime}\right)$ and BT1-R (5'-GCCTGCTGCCTTCCTTA- $\left.3^{\prime}\right)$. A DNA fragment of approximately $400 \mathrm{bp}$ was amplified and sequenced in all positives. Whenever new protozoa isolates were found, the complete 18S rRNA gene was sequenced. Measures were taken to avoid cross-contamination (laminar flow hoods, separated work areas for reaction mixture preparation, DNA extraction, amplification and analysis of PCR products, etc.) and suitable positive and negative controls were always included in amplifications. The quantitative PCR (qPCR) technique described by Criado-Fornelio et al. (2007b) was used for diagnosis of Hepatozoon sp. in carnivores. The qPCR assay was performed in an ABI 7500 fast instrument (Applied Biosystems, Inc., Foster City, CA, USA). The reaction mix included primers HEP-1 (5'-CGCGCAAATT ACCCAATT- $3^{\prime}$ ) and HEP-2 (5'-CAGACCGGTTACTTTYAGCAG- $\left.3^{\prime}\right)$. A commercial kit (iTaq SYBR Green Supermix with ROX, from BioRad-Hercules, CA, USA) was used for all qPCR amplifications. Fragments obtained in positive qPCR assays (235 bp) were sequenced for species identification. The RLB technique was performed as described by Georges et al. (2001). Amplification mix included the primers RLBF2 (5'-GACACAGGGAGGTA GTGACAAG-3') and RLB-R2 (biotin-5'-CTAAGAATTTCACCTCTGACAGT-3'). DNA electrophoresis conditions and procedures for DNA purification from agarose gels can be consulted in Criado-Fornelio et al. (2003a). DNA fragments obtained in at least two separate amplifications were sequenced using an ABI 3130 (Applied Biosystems Inc., Foster City, CA, USA) automated sequencer.

Calculation of sample size was made based on the following parameters: population size (infinite), expected prevalence $(10 \%)$, maximum error $(5 \%)$ and confidence level (95\%). A minimal sample size of 138 animals was used to estimate the prevalence of haematozoans (Thrusfield, 1995). In this respect, the total number of animals diagnosed was 383 , which means that sample size could be considered more than sufficient. The same was true when samples were divided in two groups: carnivores (159 cats and dogs) and ruminants (224 cows and sheep). Statistical analysis of prevalence data was performed with the STATGRAPHIC software package (Manugistics, Rockville, MD, USA).

\section{Results and discussion}

Table 1 shows the results of the molecular survey. Most of the protozoa isolates genetically characterized in this work were closely related to haematozoans previously identified in Europe. BLASTN ${ }^{\circledR}$ comparison of the small ribosomal subunit gene sequences always yielded identity higher than $99 \%$. By this reason, phylogenetic analyses were deemed unnecessary to identify protozoan isolates. The region where most positive samples appeared was southern France, albeit 1 cow was positive for Theileria buffeli in central France and 2 positive samples for $H$. canis (1 dog and 1 cat) came from northern France. These results are logical considering that most ruminant samples had been taken in the South of that country.

Prevalence of haematozoan infection in carnivores was close to $1 \%$ (Table 1 ). Two cats were infected with slightly different $H$. canis isolates. There was a single base difference between them, which may have been caused by a sequencing error or a single nucleotide polymorphism of the 18S rRNA gene. Both $H$. canis sequences were introduced in GenBank ${ }^{\circledR}$ with accession numbers EU622909 and EU622910, respectively. It is also interesting to note that one of the domestic cats infected by $\mathrm{H}$. canis was co-infected by Cytauxzoon sp. as well (the sequence of the latter was introduced in GenBank ${ }^{\circledR}$ with accession number EU622908). This is the first time that these two 
Table 1

Results of the molecular survey for piroplasmida and Hepatozoon sp in France.

\begin{tabular}{|c|c|c|c|}
\hline Mammal & Protozoa & No. infected/total studied - prevalence - GenBank ${ }^{\mathbb{R}}$ accession number & Closest GenBank ${ }^{\mathrm{B}}$ entry and \%identity \\
\hline Cats & $\begin{array}{l}\text { Cytauxzoon sp. } \\
\text { Hepatozoon canis }\end{array}$ & $\begin{array}{l}1 / 116-0.8 \%^{\mathrm{a}}-\mathrm{EU}_{6222908^{\mathrm{b}}} \\
2 / 116-1.7 \%-\mathrm{EU}^{\mathrm{b}} 22909^{\mathrm{b}} \text { and EU622910 }\end{array}$ & $\begin{array}{l}\text { EF0944770 }(\text { Spain })>99 \\
\text { AY461378 }(\text { Spain })>99 \\
\text { AY461378 }(\text { Spain })>99\end{array}$ \\
\hline Dogs & $\begin{array}{l}\text { Babesia canis vogeli } \\
\text { H. canis }\end{array}$ & $\begin{array}{l}1 / 108-0.9 \%-\mathrm{FJ} 213774 \\
1 / 108-0.9 \%-\mathrm{FJ} 213775\end{array}$ & $\begin{array}{l}\text { DQ439545 (Spain) } 100 \\
\text { DQ060324 (Turkey) } 100\end{array}$ \\
\hline Sheep & $\begin{array}{l}\text { Theileria ovis } \\
\text { Theileria sp. } \\
\text { Theileria sp. } \\
\text { Piroplasmida (total) }\end{array}$ & $\begin{array}{l}1 / 91-1.6 \% \text { - EU622911 } \\
1 / 91-1.6 \% \text { - FJ213777 } \\
1 / 91-1.6 \% \text { - FJ213778 } \\
3 / 91-4.8 \% \text { - not applicable }\end{array}$ & $\begin{array}{l}\text { AY533144 (Spain) }>99 \\
\text { Q866841 (Spain) } 100 \\
\text { AY262118 (China) } 100\end{array}$ \\
\hline Cows & $\begin{array}{l}\text { T. buffeli } \\
\text { B. major } \\
\text { Piroplasmida (total) }\end{array}$ & $\begin{array}{l}5 / 68-7.3 \%-\text { FJ213776 } \\
1 / 68-1.5 \% \text { - EU622907 } \\
6 / 68-8.8 \% \text { - not applicable }\end{array}$ & $\begin{array}{l}\text { DQ287959 (Spain) } 100 \\
\text { AY603399 (China) }>99\end{array}$ \\
\hline
\end{tabular}

a Cat with double infection by Cytauxzoon sp. and $H$. canis.

b New sequence reported in the present work.

haematozoans have been found in French felines. The Cytauxzoon sp from France was closely related to Spanish isolates of this protozoan obtained from both domestic cats and the Iberian lynx, as previously reported by CriadoFornelio et al. (2004) and Millán et al. (2007). The low prevalence of Cytauxzoon infection in France is in agreement with data obtained on domestic cats in Spain (CriadoFornelio et al., 2004, 2007b). In contrast with data from Portugal (Criado-Fornelio et al., 2003a) and Italy (Pennisi et al., 2007), there is no evidence of Theileria annae infection in French cats.

One dog from the Reunion Island was infected with Babesia canis vogeli (Table 1). The piroplasmid was $100 \%$ identical to isolates previously sequenced in Europe. Prevalence of canine piroplasmosis (caused by B. canis vogeli) in the sampled dogs was low $(0.9 \%)$, concurring with previous data obtained in Southern Europe (CriadoFornelio et al., 2007a). Another dog from northern France was infected with $H$. canis (1.7\% prevalence). The presence of $H$. canis in France was previously reported by Hubert et al. (2002), but molecular characterization was not included in the report. The isolate sequenced in the present study was $100 \%$ identical to $H$. canis (Kusadasy, Turkey), in agreement with previous reports by Criado-Fornelio et al. (2007b).

Ruminant piroplasmida sequenced in France were in general identical to other Theileria/Babesia isolates found in Spain or China, with two exceptions: Theileria ovis and $B$. major (these new sequences were introduced in GenBank ${ }^{\circledR}$ with accession numbers EU622911 and EU622907). Bovine theileriosis/babesiosis showed the highest prevalence (8.8\%), followed by ovine theileriosis (4.8\%). Similar infection rates were obtained in some ruminant herds from northern Spain by Nagore et al. (2004) and GarcíaSanmartín et al. (2006). Data obtained in the present study confirmed that bovines are putative carriers of piroplasmida like B. major and T. buffeli in southern and western France, in agreement with the hypothesis of L'Hostis and Seegers (2002).

Analysis of prevalence by Student $t$-test indicated that there was a significant difference $(p<0.01)$ in piroplasmida infection levels between carnivores (2/224, prevalence 0.008$)$ and ruminants (9/159, prevalence 0.05$)$. The low prevalence found in carnivores was unexpected since they were symptomatic animals. Some possible explanations for such a difference are the following: (1) sample bias. This assumption is based on the fact that most ruminant samples came from Southern France, where higher densities of tick populations can be expected due to mild climate conditions (Estrada-Peña et al., 2004), or (2) habitat differences. Most cat and dog samples were obtained in an urban environment, compared to rural habitat for cattle and sheep samples. It has been suggested that animals located in urban habitats are less exposed to tick bites than those living in rural areas (Gregoire et al., 2002).

In conclusion, there is increasing evidence (as shown in this and other, previous studies conducted by several authors) that piroplasmida and Hepatozoon are present in mammals from France and other parts of Europe with low to moderate prevalence. Further studies are necessary to detect both new hosts and "hot spots" for these pathogens. This information would prove a valuable contribution to the successful implementation of control strategies for parasitic hematozoans of domestic animals.

\section{Acknowledgments}

This work received financial support from the EC project INCO-MEDLABAB 003691. The authors also wish to thank the French veterinarians who kindly provided clinical data concerning hematozoan-infected animals.

\section{References}

Allsopp, M., Allsopp, B., 2006. Molecular sequence evidence for the reclassification of some Babesia species. Ann. N. Y. Acad. Sci. 1081, 509-517.

Anon., 2007. Opinion of the Scientific Panel on AHAW on a request from the European Commission on the risk of tick introduction into the UK, Ireland, and Malta as a consequence of abandoning the national rule. EFSA J. 13.

Bourdoiseau, G., 2006. Canine babesiosis in France. Vet. Parasitol. 138, 118-125.

Criado-Fornelio, A., Martinez-Marcos, A., Buling-Saraña, A., Barba-Carretero, J.C., 2003a. Presence of Mycoplasma haemofelis, Mycoplasma haemominutum and piroplasmids in cats from southern Europe: a molecular study. Vet. Microbiol. 93, 307-317. 
Criado-Fornelio, A., Martinez-Marcos, A., Buling-Saraña, A., Barba-Carretero, J.C., 2003b. Molecular studies on Babesia, Theileria and Hepatozoon in Southern Europe-Part I: Epizootiological aspects. Vet. Parasitol. 113, 189-201.

Criado-Fornelio, A., Gónzalez-del-Río, M.A., Buling-Saraña, A., Barba-Carretero, J.C., 2004. The "expanding universe" of piroplasms. Vet. Parasitol. 119, 337-345.

Criado-Fornelio, A., Rey-Valeiron, C., Buling, A., Barba-Carretero, J.C. Jefferies, R., Irwin, P., 2007a. New advances in molecular epizootiology of canine hematic protozoa from Venezuela, Thailand and Spain. Vet. Parasitol. 144, 261-269.

Criado-Fornelio, A., Buling, A., Cunha-Filho, N.A., Ruas, J.L., Farias, N.A., Rey-Valeiron, C., Pingret, J.L., Etievant, M., Barba-Carretero, J.C. 2007b. Development and evaluation of a quantitative PCR assay for detection of Hepatozoon sp. Vet. Parasitol. 150, 352-356.

Devos, I., Geysen, D., 2004. Epidemiological study of the prevalence of Babesia divergens in a veterinary practice in the mid-east of France. Vet. Parasitol. 125, 237-249.

Estrada-Peña, A., Martinez, J.M., Sanchez-Acedo, C., Quilez, J., Del Cacho, E., 2004. Phenology of the tick, Ixodes ricinus, in its southern distribution range (central Spain). Med. Vet. Entomol. 18, 387-397.

García-Sanmartín, J., Nagore, D., García-Pérez, A.L., Juste, R.A., Hurtado, A. 2006. Molecular diagnosis of Theileria and Babesia species infecting cattle in Northern Spain using reverse line blot macroarrays. BMC Vet. Res. 2, 16-26.

Georges, K., Loria, G.R., Riili, S., Greco, A., Caracappa, S., Jongejan, F., Sparagano, O., 2001. Detection of haemoparasites in cattle by reverse line blot hybridisation with a note on the distribution of ticks in Sicily. Vet. Parasitol. 99, 273-286.
Gratz, N., 2004. The Vector-borne Human Infections of Europe. World Health Organization Regional Office for Europe, Copenhagen, Denmark, p. 1.

Gregoire, A., Faivre, B., Heeb, P., Cezilly, F., 2002. A comparison of infestation patterns by Ixodes ticks in urban and rural populations of the Common Blackbird Turdus merula. Ibis 144, 640-645.

Harrus, S., Baneth, G., 2005. Drivers for the emergence and re-emergence of vector-borne protozoal and bacterial diseases. Int. J. Parasitol. 35, 1309-1318.

Hubert, B., Beaufils, J.P., Fabbrini, F., Magnol, J.P., 2002. Hepatozoon canis, a fortuitous or pathogenic agent in canine dermatology: a review of three cases. Vet. Dermatol. 13, 211-229.

L'Hostis, M., Seegers, H., 2002. Tick-borne parasitic diseases in cattle: current knowledge and prospective risk analysis related to the ongoing evolution in French cattle farming systems. Vet. Res. 33, 599-611.

Millán, J., Naranjo, V., Rodríguez, A., de la Lastra, J.M., Mangold, A.J., de Fuente, J., 2007. Prevalence of infection and 18S rRNA gene sequences of Cytauxzoon species in Iberian lynx (Lynx pardinus) in Spain. Parasitology 134, 995-1001.

Nagore, D., García-Sanmartín, J., García-Pérez, A.L., Juste, R.A., Hurtado, A. 2004. Identification, genetic diversity and prevalence of Theileria and Babesia species in a sheep population from Northern Spain. Int. J. Parasitol. 34, 1059-1067.

Pennisi, M.G., Alongi, A., Agnone, A., Vitale, F., Reale, S., Torina, A., 2007. Cats as reservoir of Babesia microti. In: Proceedings of the Second Babesia World Summit, University La Sapienza-Lombardo, Roma, Italy, Palermo, Italy, 4-5 May 2007. Parassitologia 49S1, p. 100.

Thrusfield, M., 1995. Epidemiological surveys. In: Veterinary Epidemiology. Blackwell Scientific, Oxford, UK, p. 183. 